\title{
3DOM- $\mathrm{NiFe}_{2} \mathrm{O}_{4}$ as an effective catalyst for turning $\mathrm{CO}_{2}$ and $\mathrm{H}_{2} \mathrm{O}$ into fuel $\left(\mathrm{CH}_{4}\right)$
}

\author{
Yanan Ren ${ }^{1} \cdot$ Dongmei Zheng ${ }^{1} \cdot$ Linyan $\mathrm{Liu}^{1} \cdot$ Qiangsheng Guo ${ }^{2} \cdot \mathrm{Na} \mathrm{Sha}^{2} \cdot$ Zhe Zhao $^{1,3}$
}

Published online: 30 October 2018

(c) The Author(s) 2018

\section{Abstract}

Three-dimensional ordered macroporous $\mathrm{NiFe}_{2} \mathrm{O}_{4}$ (3DOM-NFO) powder was synthesized through the direct templating method combined with the sol-gel combustion technique. Polymethyl methacrylate (PMMA) spheres with different sizes were used as the hard templates. In order to understand the effect of PMMA spheres mean size on the structure and catalytic activity of synthesized 3DOM-NFO, the detailed characterization of the material was carried out by XRD, SEM, BET, XPS, UV-VIS, and DRS techniques. Direct hydrogeneration production of $\mathrm{CH}_{4}$ from $\mathrm{CO}_{2}$ and $\mathrm{H}_{2} \mathrm{O}$ was used to evaluate the catalysis performance of 3DOM-NFOs. The production of $\mathrm{CH}_{4}$ evolution can reach $1040.8 \mu \mathrm{mol} / \mathrm{g}$ at $350{ }^{\circ} \mathrm{C}$ and ambient pressure when $300 \mathrm{~nm}$ template was used. It was concluded that the specific surface area and moderate concentration of oxygen vacancies are the crucial factors affecting the catalysis properties. Reasonably high turnover number of 0.244 and high $\mathrm{CH}_{4}$ conversion efficiency of $0.897 \%$ were obtained in this study. 3DOM-NFO can be a promising catalyst for hydrocarbon fuel production by directly using $\mathrm{CO}_{2}$ and $\mathrm{H}_{2} \mathrm{O}$ as the safe and cheap feedstocks.

\section{Graphical Abstract}

$\mathrm{CH}_{4}$ evolution over time for different 3DOM-NFO catalysts at $350{ }^{\circ} \mathrm{C}$.

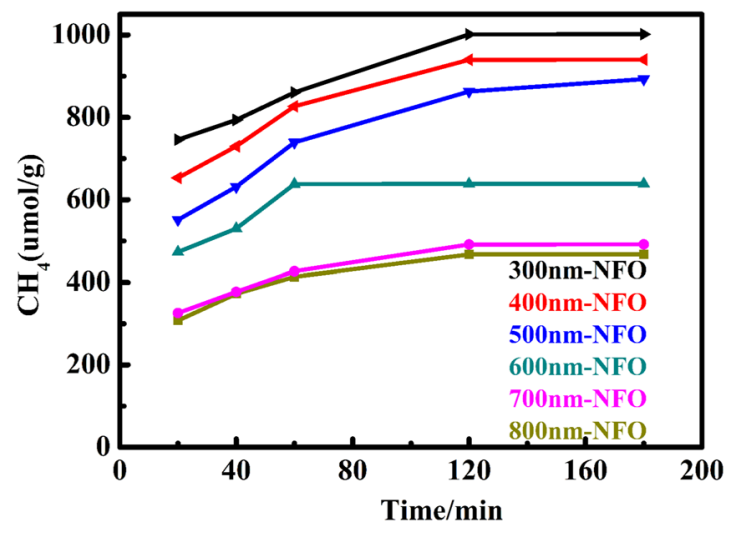

Electronic supplementary material The online version of this article (https://doi.org/10.1007/s10971-018-4816-6) contains supplementary material, which is available to authorized users.

Zhe Zhao

zhezhao@kth.se

Na Sha

shana@sit.edu.cn

1 School of Materials Science and Engineering, Shanghai Institute of Technology, 201418 Shanghai, China

2 School of Chemical and Environmental Engineering, Shanghai Insititute of Technology, 201418 Shanghai, China

3 Department of Materials Science and Engineering, KTH Royal Institute of Technology, 10044 Stockholm, Sweden 


\section{Highlights}

- 3DOM-NiFe $\mathrm{O}_{4-\delta}$ can be synthesized successfully by using PMMA spheres as the hard template.

- A high $\mathrm{CH}_{4}$ selectivity of $>99 \%$ can be obtained for all 3DOM-NFO materials.

- For $50 \mathrm{mg}$ catalyst, NFO-300 can promise a yield of $0.897 \%$ for the direct conversion of $\mathrm{CO}_{2}$ and $\mathrm{H}_{2} \mathrm{O}$ to $\mathrm{CH}_{4}$ at $350{ }^{\circ} \mathrm{C}$ and ambient pressure.

- 3DOM-NFO catalyst developed in this study can be a very promising catalyst for hydrocarbon fuel production by directly using $\mathrm{CO}_{2}$ and $\mathrm{H}_{2} \mathrm{O}$ as the safe and cheap resources.

Keywords $\mathrm{NiFe}_{2} \mathrm{O}_{4} \cdot$ Templating method $\cdot$ Sol-gel combustion $\cdot$ Oxygen vacancies $\cdot$ Hydrogeneration

\section{Introduction}

Due to rapid industrialization, the over-consumption of fossil fuel reserves is accompanied with large anthropogenic $\mathrm{CO}_{2}$ discharge, which is outpacing nature's $\mathrm{CO}_{2}$ recycling capability and destroying the ecological balance, causing significant environmental harm, such as global warming and glaciers melting [1-3]. Meanwhile, the stock of oil and gas are not enough for a sustainable development in the future $[4,5]$. The use of catalyst to chemically reduce $\mathrm{CO}_{2}$ into hydrocarbon fuels, such as methanol or methane offers an efficient and feasible alternative to solve these problems [6]. It is a desirable goal to design and synthesize highefficiency catalysts to convert $\mathrm{CO}_{2}$ into fuels and chemicals [7].

Since Halmann [8] and Inoue [9] reported their pioneer work on the semiconductor photocatalysts for reduction of $\mathrm{CO}_{2}$, many photocatalysts, such as $\mathrm{TiO}_{2}$ [10-12], g- $\mathrm{C}_{3} \mathrm{~N}_{4}$ [13], $\mathrm{Bi}_{2} \mathrm{WO}_{6}$ [14] $\mathrm{SnNb}_{2} \mathrm{O}_{4}$ [15] $\mathrm{LaSrCoFeO}_{6-\delta}$ [16], $\mathrm{ZnO} @ \mathrm{Cu}-\mathrm{Zn}-\mathrm{Al}$ [17], have been developed for turning $\mathrm{CO}_{2}$ into valuable hydrocarbon fuels, mostly in the form of $\mathrm{CH}_{4}$. A photocatalyst is usually a semiconductor material which absorbs light, separates the photogenerated charges, transports them to the surface, and provides active sites for the catalytic reaction. However, the best $\mathrm{CH}_{4}$ evolution performance is still less than $600 \mu \mathrm{mol} / \mathrm{g}$. The reason is that breaking down $\mathrm{C}-\mathrm{O}$ bonds needs higher energy. It was reported that an oxygen-deficient magnetite can break the chemical bond of $\mathrm{CO}_{2}$ to form carbon at $300{ }^{\circ} \mathrm{C}$ [18], and the oxygen vacancies can enhance catalytic activity [19]. It is obvious that new catalysis process need to be explored. To consider the fact that most well-developed catalysis for organic synthesis is based on thermally driven process, then solar-driven thermochemical conversion can be one good option to be selected [20]. It will be a highly efficient way of using oxygen-deficient magnetite as catalyst for converting $\mathrm{CO}_{2}$ hydrocarbon fuels on thermal reactions. Thanks to many well-designed solar irradiation collectors, solar-driven thermochemical reaction strategy can be easily implemented in reality. The key factor affecting the catalysis performance of catalyst is the concentration of oxygen vacancies [21, 22].
$\mathrm{NiFe}_{2} \mathrm{O}_{4}$, as a typical semiconductor material, was often used to carry out the redox reactions because the Fe ion exists as both bivalent and trivalent species [23]. It also shows an excellent chemical stability that has the advantage of low cost and simple preparation process. Based on these basic characteristics, we have demonstrated in our previous work that $\mathrm{NiFe}_{2} \mathrm{O}_{4}$ nanoparticles synthesized through solvothermal method can be a good catalyst to transform $\mathrm{CO}_{2}$ and $\mathrm{H}_{2} \mathrm{O}$ into $\mathrm{CH}_{4}$ with almost $99.9 \%$ selectivity [24]. However, the $\mathrm{CH}_{4}$ evolution rate is up to $357.6 \mu \mathrm{mol} / \mathrm{g}$, which is still not high enough to make this material competitive for real application. A potential strategy for better catalysis performance is to increase surface area further.

This paper uses PMMA as the hard template, which was prepared by a convenient and efficient modified sol-gel combustion process to synthesize the $3 \mathrm{DOM}-\mathrm{NiFe}_{2} \mathrm{O}_{4}$. The $\mathrm{NiFe}_{2} \mathrm{O}_{4}$ catalyst with higher specific surface area can be realized by such three-dimensional ordered macroporous structure $[25,26]$. The unique ordered macroporous structure can display highly efficient ability for the adsorption of $\mathrm{CO}_{2}$ and improve the transport and separation of electronhole pairs [27]. Therefore, we report the preparation, characterization, and the catalytic properties of the threedimensional ordered macroporous $\mathrm{NiFe}_{2} \mathrm{O}_{4}$ (3DOM-NFO) catalyst. The aim of this work was to investigate the effects of specific surface area and the concentration of oxygen vacancies on the catalytic reaction, crystal structure, catalytic performance, and thermal reaction mechanisms of the 3DOM-NFO for the $\mathrm{CO}_{2}$ reduction.

\section{Experimental}

\subsection{Synthesis of polymethyl methacrylate (PMMA) microspheres}

PMMA spheres were synthesized by literature techniques $[16,28]$. Potassium persulfate $(6.0 \mathrm{mmol})$ and water $(720$ $\mathrm{mL}$ ) were stirred at $300 \mathrm{rpm}$, heated at $90^{\circ} \mathrm{C}$, retained for $30 \mathrm{~min}$, and degassed with flowing nitrogen in a separable three-neck $250 \mathrm{~mL}$ round-bottom flask. Methyl methacrylate (MMA, $748 \mathrm{mmol}$ ) was poured into the flask, and the 
resulting suspension was stirred at $90^{\circ} \mathrm{C}$ for $0.5,1,1.5,2,4$, and $6 \mathrm{~h}$, respectively. The PMMA colloidal crystal template was prepared by centrifugation $(2500 \mathrm{rpm})$ of the colloidal suspension in a $50 \mathrm{~mL}$ centrifugation tube for $2 \mathrm{~h}$. The different size template was obtained.

\subsection{Preparation of 3DOM-NFO powders}

The 3DOM-NFO powders were prepared by templating combined with sol-gel combustion method. A metal nitrate hydrate mixture (mole ratio: $0.015 \mathrm{M}$ ) and equal mole of citric acid $\mathrm{C}_{6} \mathrm{H}_{8} \mathrm{O}_{7}$ hydrate mixture was dissolved with $8 \mathrm{~mL}$ of ethyleneglycol (EG) by stirring in a $100 \mathrm{~mL}$ beaker at room temperature for $2 \mathrm{~h}$, and the produced EG solution was poured into a $25 \mathrm{~mL}$ volumetric flask. Methanol $(8 \mathrm{~mL})$ and EG were added in amounts necessary to achieve the desired concentration (the final concentration of methanol was 32 vol\%). Then, the PMMA samples were soaked in the solution for $2 \mathrm{~h}$. Excess solution was removed from the impregnated PMMA samples by vacuum filtration. After aging for $24 \mathrm{~h}$ in air it turned into a gel. A $0.5 \mathrm{~g}$ amount of the sample was mixed with $2.5 \mathrm{~g}$ of quartz sand (10-15 mesh) and calcined in a tubular furnace (inner diameter ca. $12 \mathrm{~mm}$ ) in an air flow of $50 \mathrm{~mL}$ min. The temperature was raised at a rate of $1{ }^{\circ} \mathrm{C} / \mathrm{min}$ to $600{ }^{\circ} \mathrm{C}$ and held for $5 \mathrm{~h}$. the obtained powders were named $300 \mathrm{~nm}-\mathrm{NFO}, 400 \mathrm{~nm}-\mathrm{NFO}$, $500 \mathrm{~nm}-\mathrm{NFO}, 600 \mathrm{~nm}-\mathrm{NFO}, 700 \mathrm{~nm}-\mathrm{NFO}$, and $800 \mathrm{~nm}-$ NFO.

\subsection{Evaluation of catalytic activity}

The thermocatalytic experiments were carried out in a gasclosed circulation system as shown in Fig. $1.50 \mathrm{mg}$ of the powder was uniformly placed at the bottom of a quartz reactor. The thermocatalytic activity evaluation was performed at $350{ }^{\circ} \mathrm{C}$, which was kept through the heating jacket in out of the reactor and the temperature control device. In a period of insulation for $3 \mathrm{~h}$, samples were taken every hour and quantitative analysis was performed on GSTek (Echromtek A90) equipment with a capillary column. The quantification of $\mathrm{CH}_{4}$ yield was based on the external standard and the use of calibration curve.

\section{Results and discussion}

The PMMA spheres average particle size were characterized by Malvern size analyzer. Figure $2 \mathrm{a}$ shows that the PMMA spheres with different sizes were successfully synthesized. With the increase of PMMA sphere size, the size distribution becomes wider and harder to control. The XRD pattern of 3DOM-NFO particles templated by 300 , 400, and $500 \mathrm{~nm}$ PMMA spheres can be indexed as the pure $\mathrm{NiFe}_{2} \mathrm{O}_{4}$ phase (PDF\#01-086-2267), characteristic diffraction peaks at $2 \theta\left(^{\circ}\right)=30.3,35.6,37.3,43.3,53.8,57.4$, and 63.0 can be indexed as ( 200$),\left(\begin{array}{lll}3 & 1 & 1\end{array}\right),\left(\begin{array}{ll}2 & 2\end{array}\right),\left(\begin{array}{lll}4 & 0\end{array}\right),(42$ 2), ( $\left.\begin{array}{lll}5 & 1 & 1\end{array}\right)$, and $\left(\begin{array}{lll}4 & 4 & 0\end{array}\right)$ planes of face-centered cubic

Fig. 1 Schematic diagram for catalysis performance test
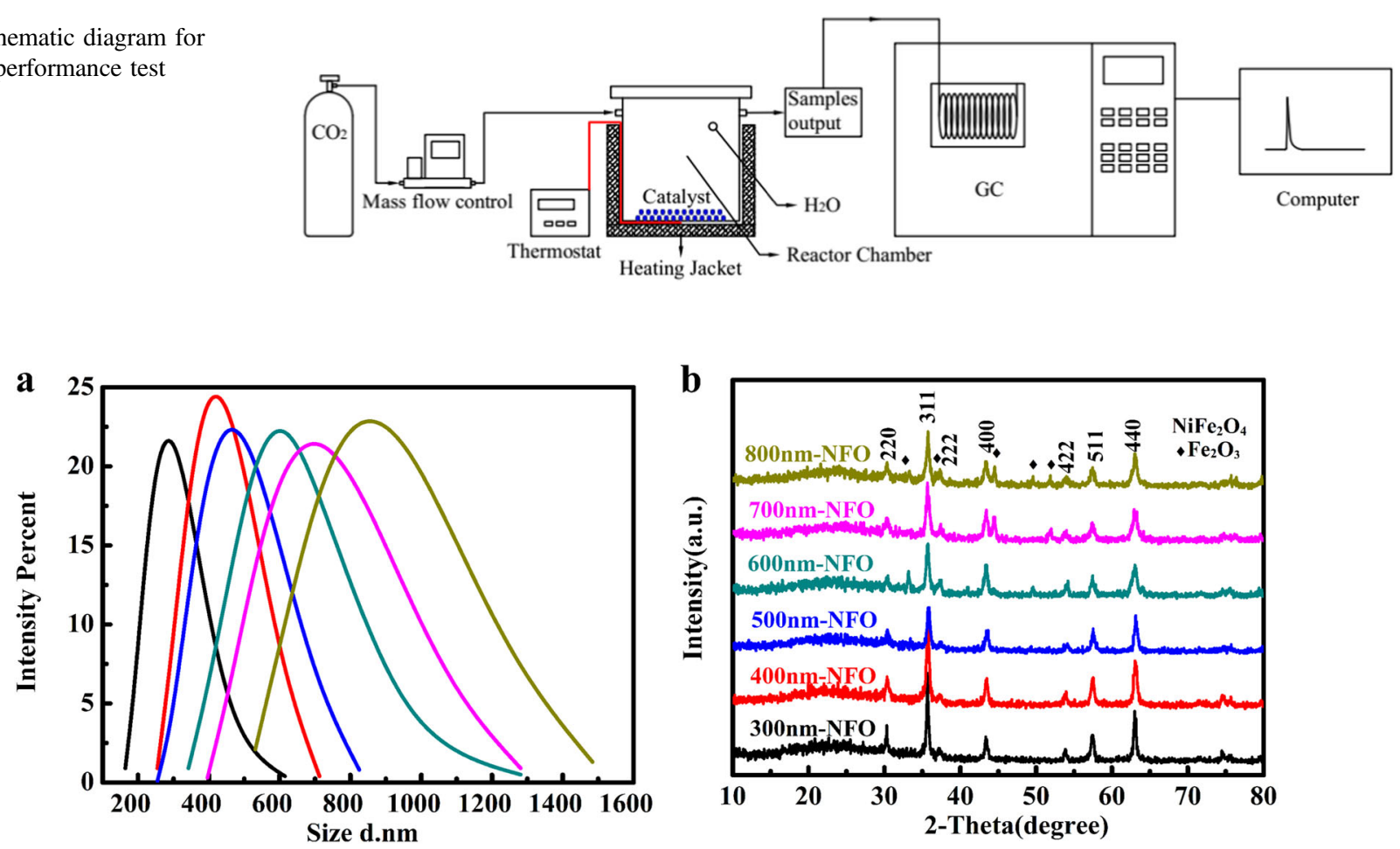

Fig. 2 a Average particle size distribution of PMMA spheres. b XRD pattern of 3DOM-NFO particles 
Table 1 The XRD analysis and BET results of different 3DOMNFO particles

\begin{tabular}{llllll}
\hline Sample & $S_{\text {BET }}\left(\mathrm{m}^{2} / \mathrm{g}\right)$ & $2 \theta(311)\left(^{\circ}\right)$ & $d_{311}(\mathrm{~nm})$ & Unit cell $a, b, c(\mathrm{~nm})$ & Crystallite size $(\mathrm{nm})$ \\
\hline $300 \mathrm{~nm}-\mathrm{NFO}$ & 153.3 & 35.683 & 0.2514 & 0.8344 & 27.2 \\
$400 \mathrm{~nm}-\mathrm{NFO}$ & 132.2 & 35.723 & 0.2511 & 0.8330 & 22.5 \\
$500 \mathrm{~nm}-\mathrm{NFO}$ & 123.0 & 35.799 & 0.2506 & 0.8316 & 20.5 \\
$600 \mathrm{~nm}-\mathrm{NFO}$ & 114.6 & 35.719 & 0.2512 & 0.8322 & 19.9 \\
$700 \mathrm{~nm}-\mathrm{NFO}$ & 99.6 & 35.681 & 0.2514 & 0.8332 & 19.7 \\
$800 \mathrm{~nm}-\mathrm{NFO}$ & 94.6 & 35.758 & 0.2509 & 0.8331 & 20.0 \\
\hline
\end{tabular}

Fig. 3 SEM images of 3DOMNFO synthesized by using different PMMA spheres of a $300 \mathrm{~nm}, \mathbf{b} 600 \mathrm{~nm}$, and c 800 nm. d PMMA spheres of $300 \mathrm{~nm}$ and e PMMA spheres of $600 \mathrm{~nm}$

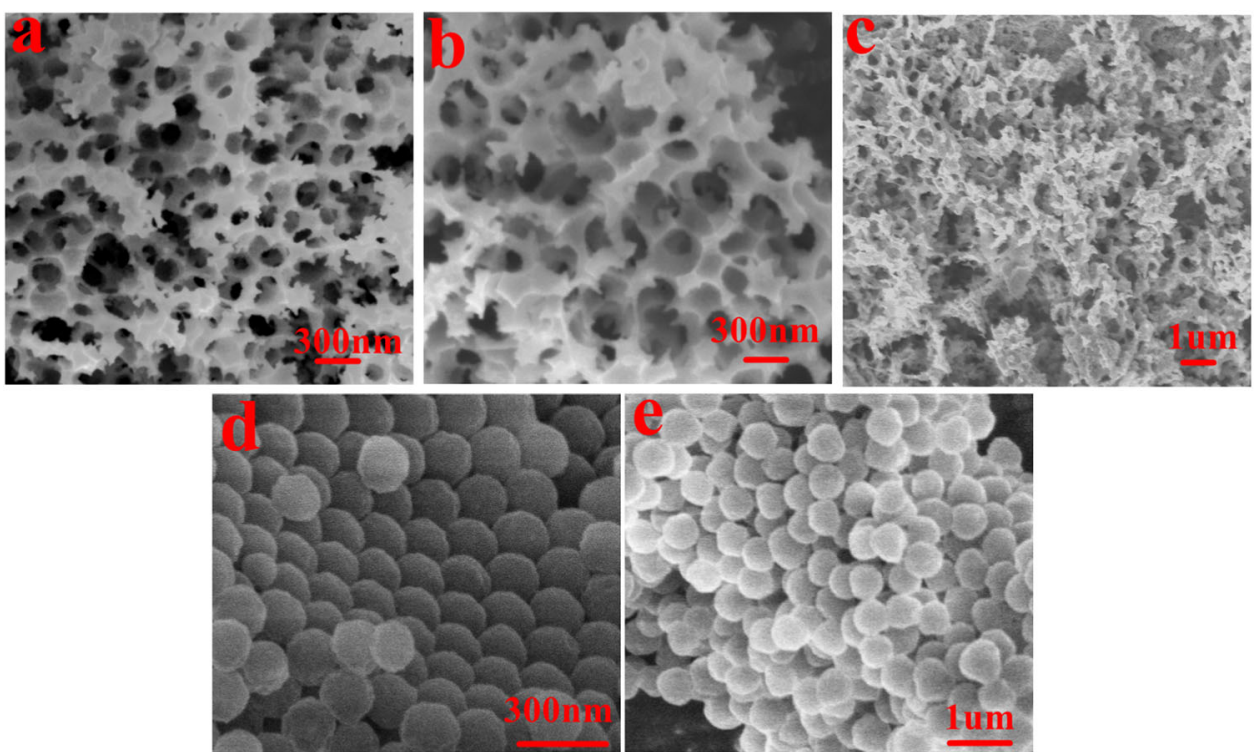

structure. For PMMA template spheres larger than $500 \mathrm{~nm}$, impurity $\alpha-\mathrm{Fe}_{2} \mathrm{O}_{3}$ phase (PDF \#00-001-1053) can be clearly indexed in the XRD pattern (see Fig. 2b). Because the combustion of PMMA is an exothermic reaction, the local temperature is higher with the PMMA size increasing, this can be the key reason for the admixture formation. As seen from the data presented in Table 1, the crystallite size of 3DOM-NFO particles was determined using DebyeScherrer's formula and found to be in the range of 19-28 $\mathrm{nm}$. The BET-specific surface area decreases as the PMMA sphere size increase.

The SEM images of 3DOM-NFO catalysts and the PMMA colloidal crystal templates were clearly presented in Fig. 3. Except for the largest PMMA template size of 800 $\mathrm{nm}$, the other 3DOM-NFO particles still reserved the original colloidal packing structure of spheres. The PMMA template ordered structure was replicated into $\mathrm{NiFe}_{2} \mathrm{O}_{4}$, we obtained the catalyst with macroporous structure successfully. The damage of the original packing structure in the $800 \mathrm{~nm}$ case can be linked with the higher local temperature during the combustion synthesis process. The local temperature linked with excess exothermal energy from relatively larger PMMA spheres seems to negatively affect both purity control and 3DOM structure reservation.

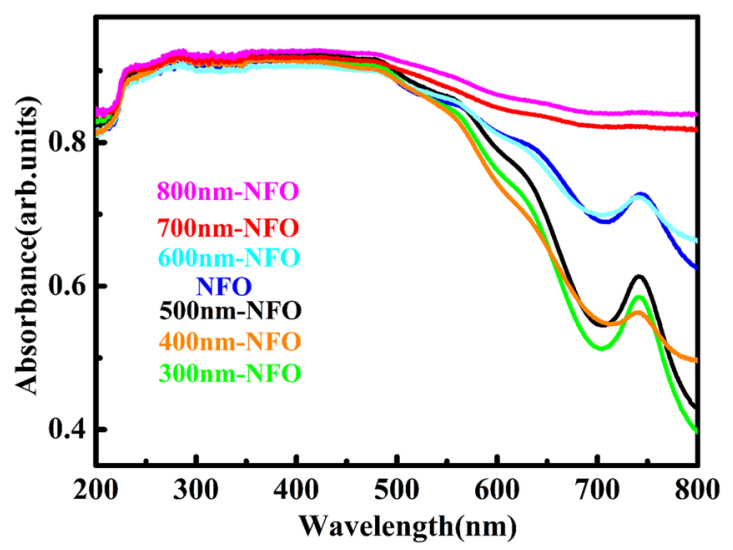

Fig. 4 UV-vis diffuse reflectance spectra of different 3DOM-NFO samples (indicated by different PMMA template sizes)

UV-vis diffuse reflectance spectra were measured and are shown in Fig. 4. For the samples of 300, 400, 500, 600 $\mathrm{nm}$, the absorption peak around $740 \mathrm{~nm}$ is actually the characteristic absorption of $\mathrm{NiFe}_{2} \mathrm{O}_{4}$. This peak was totally smeared out in 700 and $800 \mathrm{~nm}$ samples due to the very much improved visible light absorption. The improved visible light absorption might be also linked with the high 
local calcination temperature [29]. Higher temperature may introduce more oxygen vacancies in lattice and hence generate more intermediate energy levels in the band gap.

As shown in Table 1 and Fig. 5, the BET-specific surface areas of six $3 \mathrm{DOM}-\mathrm{NiFe}_{2} \mathrm{O}_{4}$ samples changed with template sphere size, but the characteristic $\mathrm{N}_{2}$-adsorption/desorption isotherms are rather similar, all presented with mesoporous pore channels. Specific surface area decreased from 153.3 to

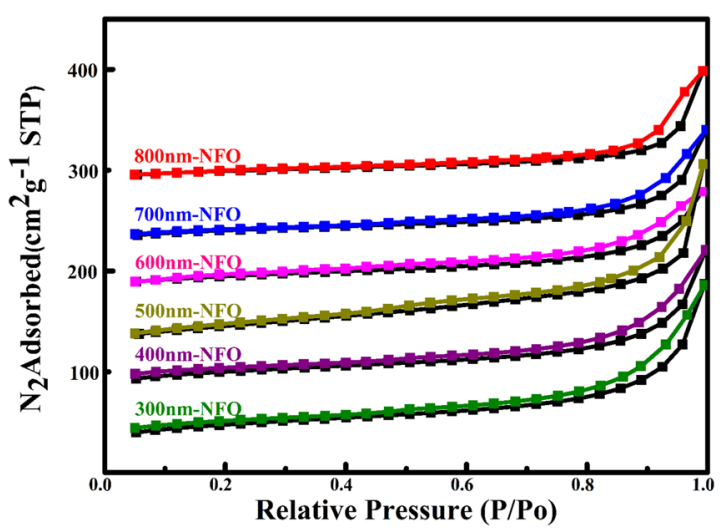

Fig. $5 \mathrm{~N}_{2}$ adsorption/desorption isotherm curves of 3DOM-NFOs
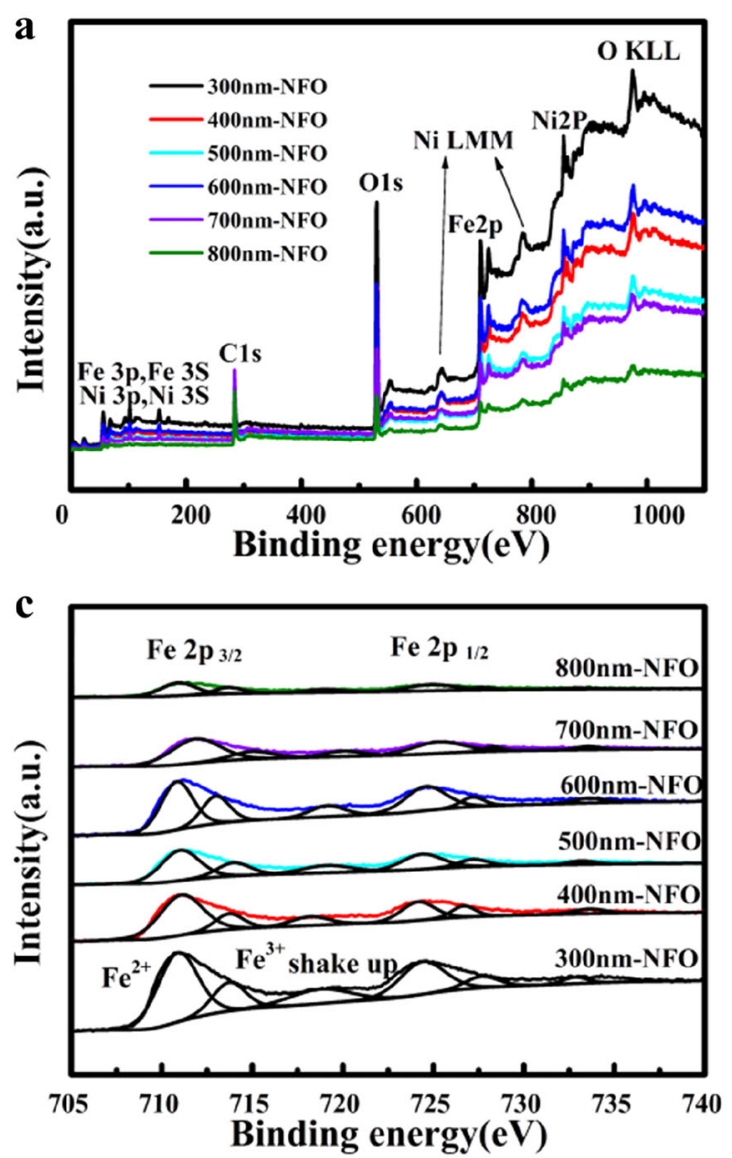

$94.6 \mathrm{~m}^{2} / \mathrm{g}$ when the template sphere size increased from 300 to $800 \mathrm{~nm}$. Compared with the specific surface area of $<25$ $\mathrm{m}^{2} / \mathrm{g}$ achieved with the solvothermally synthesized NFO nanoparticles [24], it is obvious that 3DOM structure is one efficient strategy to increase the surface area of catalyst. Larger surface area can lead to more reaction sites for $\mathrm{CO}_{2}$ reduction.

$\mathrm{X}$-ray photoelectron spectroscopy was used to investigate the chemical state and surface composition of the 3DOM-NFOs (see Fig. 6). Tables 2 and 3 list the key summary of such a XPS analysis. As shown in Fig. 6, the survey spectra (Fig. 6a) show peaks that are ascribed to Ni, $\mathrm{Fe}, \mathrm{O}$, and C. In Fig. 6b, The O $1 s$ peak of 3DOM-NFOs (Fig. 6b) showed three Gaussian features at 530.2, 532.2, $533.5 \mathrm{eV}$, corresponding to the low, medium, and high binding energy peaks, respectively. which were attributed to lattice, surface, and adsorbed oxygen, respectively [30, 31]. In this case, it is possible to analyze the oxygen vacancies based on the previous reported methods [32, 33]. It has been reported that the surface oxygen component develops with the increase of oxygen vacancies [34], which can lead to the asymmetry of the main peak. Higher surface/lattice ratio indicate that more oxygen vacancies exist in the surface of
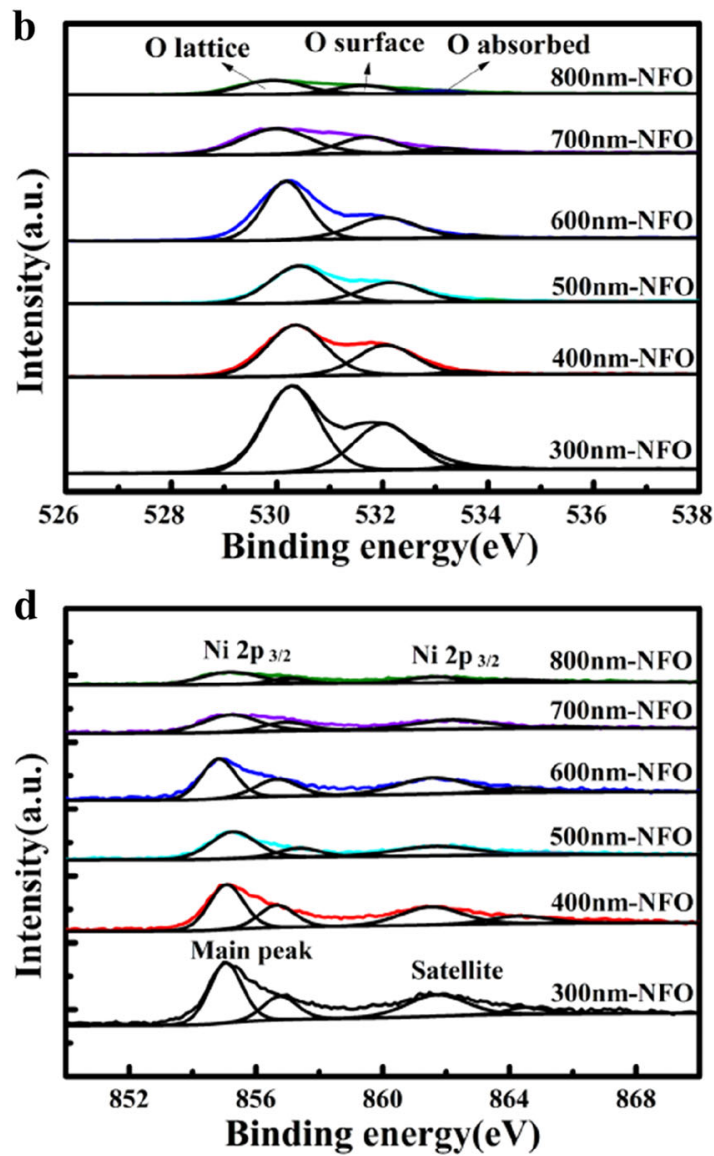

Fig. 6 The XPS spectra of a survey, b O $1 s$, c Fe $2 p$, and d Ni $2 p$ of 3DOM-NFOs 
Table 2 The relative concentrations of surface and lattice oxygen

\begin{tabular}{lllllll}
\hline O $1 s(\mathrm{eV})$ & $\begin{array}{l}300 \mathrm{~nm}- \\
\text { NFO }\end{array}$ & $\begin{array}{l}400 \mathrm{~nm}- \\
\text { NFO }\end{array}$ & $\begin{array}{l}500 \mathrm{~nm}- \\
\text { NFO }\end{array}$ & $\begin{array}{l}600 \mathrm{~nm}- \\
\text { NFO }\end{array}$ & $\begin{array}{l}700 \mathrm{~nm}- \\
\text { NFO }\end{array}$ & $\begin{array}{l}800 \mathrm{~nm}- \\
\text { NFO }\end{array}$ \\
\hline Lattice oxygen & 61.66 & 61.78 & 63.49 & 64.28 & 60.73 & 59.69 \\
Surface oxygen & 36.25 & 36.19 & 35.21 & 33.5 & 32.36 & 31.78 \\
Absorbed oxygen & 2.09 & 2.03 & 1.30 & 2.22 & 6.91 & 8.53 \\
Surface/lattice & 0.59 & 0.59 & 0.55 & 0.52 & 0.53 & 0.53 \\
\hline
\end{tabular}

Table 3 XPS-binding energies relative to the 3DOM-NFO. The relative concentrations of surface and lattice oxygen

\begin{tabular}{llllll}
\hline Catalyst & Fe $2 p(\mathrm{eV})$ & & Ni $2 p(\mathrm{eV})$ & \\
\cline { 2 - 3 } \cline { 6 - 6 } & $\mathrm{Fe} 2 p_{3 / 2}$ & Fe $2 p_{1 / 2}$ & & Ni $2 p_{3 / 2}$ & Ni $2 p_{1 / 2}$ \\
\hline \multirow{2}{*}{$300 \mathrm{~nm}-\mathrm{NFO}$} & $710.88(74.58 \%)$ & $724.41(79.28 \%)$ & & $855.05(70.91 \%)$ & $861.70(82.93 \%)$ \\
& $713.72(25.42 \%)$ & $727.67(20.72 \%)$ & & $856.76(29.09 \%)$ & $864.51(17.07 \%)$ \\
$400 \mathrm{~nm}-\mathrm{NFO}$ & $711.08(79.39 \%)$ & $724.16(70.08 \%)$ & & $855.07(66.10 \%)$ & $861.52(72.06 \%)$ \\
& $713.72(20.61 \%)$ & $726.67(29.92 \%)$ & & $856.66(33.90 \%)$ & $864.33(27.94 \%)$ \\
$500 \mathrm{~nm}-\mathrm{NFO}$ & $711.02(72.21 \%)$ & $724.38(73.30 \%)$ & & $855.16(72.67 \%)$ & $861.84(79.43 \%)$ \\
& $713.97(27.79 \%)$ & $727.19(26.70 \%)$ & & $856.82(27.33 \%)$ & $865.16(20.57 \%)$ \\
$600 \mathrm{~nm}-\mathrm{NFO}$ & $710.83(66.70 \%)$ & $724.58(81.25 \%)$ & & $854.82(65.32 \%)$ & $861.58(83.44 \%)$ \\
& $713.98(33.30 \%)$ & $727.17(18.75 \%)$ & & $856.66(34.68 \%)$ & $864.33(16.56 \%)$ \\
$700 \mathrm{~nm}-\mathrm{NFO}$ & $711.88(78.56 \%)$ & $725.29(87.12 \%)$ & & $855.20(71.64 \%)$ & $862.10(87.53 \%)$ \\
& $714.99(21.44 \%)$ & $728.28(12.88 \%)$ & & $856.94(28.36 \%)$ & $865.70(12.47 \%)$ \\
$800 \mathrm{~nm}-\mathrm{NFO}$ & $710.91(70.80 \%)$ & $724.88(85.18 \%)$ & & $855.19(78.12 \%)$ & $861.67(62.11 \%)$ \\
& $713.69(29.20 \%)$ & $727.70(14.82 \%)$ & & $857.02(21.88 \%)$ & $864.17(37.89 \%)$ \\
\hline
\end{tabular}

listed in Table 3 . The binding energy of $\mathrm{Ni} 2 p$ were resolved by 855 and 857 for Ni $2 p_{3 / 2}$ and 862 and $864 \mathrm{eV}$ for Ni $2 p_{1 /}$ 2 , respectively, which are similar to previously reported values [33]. Similarly, Fe $2 p$ orbital were also resolved by 711 and $714 \mathrm{eV}$ for $\mathrm{Fe} 2 p_{3 / 2}$ and 724 and $727 \mathrm{eV}$ for $\mathrm{Fe} 2 p_{1 /}$ ${ }_{2}[16,35]$. However, a thorough analysis of the valence state in 3DOM-NFOs cannot lead to any consistent tendency when the template size was changed from 300 to $800 \mathrm{~nm}$. It was so expected that it should be the specific surface area playing the key role for catalysis performance if finally a noticeable difference can be clarified in $\mathrm{CO}_{2}$ hydrogeneration test.

In Fig. 7, the evolution of $\mathrm{CH}_{4}$ with prolonged reaction time were presented for various 3DOM-NFOs. Among them, NFO-300 nm presented best performance with a cumulative yield of $\mathrm{CH}_{4}$ up to $1040.8 \mu \mathrm{mol} / \mathrm{g}$ in $180 \mathrm{~min}$. This value is four times of the best result we obtained in previous study and actually the reaction was finished in shorter time [25]. After the first two hours, the catalysis reaction almost reached the equilibrium state. It is also very interesting that we still get a very high selectivity (>99\%, see Table 3) of $\mathrm{CH}_{4}$. As we already discussed before, we can only identify specific area as the changing factor for different 3DOM-NFOs, It is more rational to ascribe the improvement of catalysis performance to the increased surface area in $300 \mathrm{~nm}-\mathrm{NFO}$. Furthermore, if we compare 
Table 4 Summary of yield and TON of $\mathrm{CH}_{4}$ for different 3DOMNFOs

\begin{tabular}{llll}
\hline Samples & Yield $(\%)^{\mathrm{a}}\left(\mathrm{CH}_{4}\right)$ & $\mathrm{TON}^{\mathrm{b}}\left(\mathrm{CH}_{4}\right)$ & Selectivity $(\%)$ \\
\hline $300 \mathrm{~nm}-\mathrm{NFO}$ & 0.897 & 0.244 & $>99$ \\
$400 \mathrm{~nm}-\mathrm{NFO}$ & 0.810 & 0.220 & $>99$ \\
$500 \mathrm{~nm}-\mathrm{NFO}$ & 0.769 & 0.209 & $>99$ \\
$600 \mathrm{~nm}-\mathrm{NFO}$ & 0.550 & 0.150 & $>99$ \\
$700 \mathrm{~nm}-\mathrm{NFO}$ & 0.423 & 0.115 & $>99$ \\
$800 \mathrm{~nm}-\mathrm{NFO}$ & 0.403 & 0.110 & $>99$ \\
\hline
\end{tabular}

${ }^{a}$ Moles of product $\left(\mathrm{CH}_{4}\right)$ per mole of $\mathrm{CO}_{2}$

${ }^{\mathrm{b}}$ Turn over number $=$ number of moles of product per mol of catalyst material

the evolution of $\mathrm{CH}_{4}$ between various 3DOM-NFOs, the difference is roughly linearly linked with the change of surface area. Taking count of previous study with NFO, the improved $\mathrm{CH}_{4}$ yield in this study can also be explained by the increased specific surface area. So the basic mechanism for $\mathrm{CO}_{2}$ hydrogeneration with our NFOs should be the same as the one suggested by previous studies [25, 36, 37]. It was reported that $\mathrm{NiFe}_{2} \mathrm{O}_{4}$ with oxygen vacancies could transform $\mathrm{H}_{2} \mathrm{O}$ into $\mathrm{H}$ under $350{ }^{\circ} \mathrm{C}$ (Eq. (1)) [36]. 3DOM$\mathrm{NiFe}_{2} \mathrm{O}_{4-\delta}$ with more oxygen vacancies decomposes $\mathrm{CO}_{2}$ into $\mathrm{C}$ around $350^{\circ} \mathrm{C}$ (Eq. (2)) [37]. The generated carbon from the splitting of $\mathrm{CO}_{2}$ will react with the hydrogen intermediate to form $\mathrm{CH}_{4}$ (Eq. (3)) [24]. The high selectivity of $>99 \%$ obtained in this study should be linked with the limited kinds of intermediate products possibly existed in our study. Very possibly, we have freshly formed $\mathrm{C}$ and $\mathrm{H}$ as the main intermediate molecules for $\mathrm{CH}_{4}$ formation. But this is still a tentative proposal, which may need further detailed study.

$\mathrm{NiFe}_{2} \mathrm{O}_{4-\delta}+\left(\delta-\delta^{\prime}\right) \mathrm{H}_{2} \mathrm{O} \rightarrow \mathrm{NiFe}_{2} \mathrm{O}_{4-\delta^{\prime}}+2\left(\delta-\delta^{\prime}\right) \mathrm{H}$,

$\mathrm{NiFe}_{2} \mathrm{O}_{4-\delta}+\left(\delta-\delta^{\prime}\right) / 2 \mathrm{CO}_{2} \rightarrow \mathrm{NiFe}_{2} \mathrm{O}_{4-\delta^{\prime}}$ $+\left(\delta-\delta^{\prime}\right) / 2 \mathrm{C}\left(\delta>\delta^{\prime}\right)$,

$\mathrm{C}+4 \mathrm{H} \rightarrow \mathrm{CH}_{4}$.

The yield of $\mathrm{CH}_{4}$ can reach $0.897 \%$ (more details can be found in Table 4) and it can be anticipated to reach much better result if an industrial relevant condition. A turn over number (TON) of 0.244 was also recorded for $300 \mathrm{~nm}$ NFO. To be more precise, there are still very limited catalyst which can realize efficient $\mathrm{CO}_{2}$ hydrogeneration by using $\mathrm{H}_{2} \mathrm{O}$ instead of $\mathrm{H}_{2}$. 3DOM-NFO can be an efficient $\mathrm{CO}_{2}$ hydrogeneration catalyst with low cost.

\section{Conclusion}

3DOM-NiFe ${ }_{2} \mathrm{O}_{4-\delta}$ can be synthesized successfully by using PMMA spheres as the hard template. Reasonably high specific surface area can be realized by this template strategy when combined with a sol-gel combustion method. The specific surface area is the key factor affecting the final catalysis performance for the reduction of $\mathrm{CO}_{2}$ and $\mathrm{H}_{2} \mathrm{O}$ to form hydrocarbon fuel $\mathrm{CH}_{4}$. A high $\mathrm{CH}_{4}$ selectivity of $>99 \%$ can be obtained for all 3DOM-NFOS. For $50 \mathrm{mg} 300$ nm-NFO catalyst, the best production of $\mathrm{CH}_{4}$ evolution can reach $1040.8 \mu \mathrm{mol} / \mathrm{g}$ for the direct conversion of $\mathrm{CO}_{2}$ and $\mathrm{H}_{2} \mathrm{O}$ to $\mathrm{CH}_{4}$ at $350{ }^{\circ} \mathrm{C}$ and ambient pressure. A reasonably good TON of 0.244 was also reported for $300 \mathrm{~nm}-\mathrm{NFO}$. 3DOM-NFO catalyst developed in this study can be a very promising catalyst for hydrocarbon fuel production by directly using $\mathrm{CO}_{2}$ and $\mathrm{H}_{2} \mathrm{O}$ as the safe and cheap resources.

Acknowledgements This research is supported by National Key R\&D Program of China (No. 2017YFB1103500).

Open Access This article is distributed under the terms of the Creative Commons Attribution 4.0 International License (http://crea tivecommons.org/licenses/by/4.0/), which permits use, duplication, adaptation, distribution, and reproduction in any medium or format, as long as you give appropriate credit to the original author(s) and the source, provide a link to the Creative Commons license, and indicate if changes were made.

\section{References}

1. Raper SC, Braithwaite RJ (2006) Nature 439:311-313

2. Yang ZZ, He LN, Gao J et al. (2012) Energy Environ Sci 5:66026639

3. Olah GA, Prakash GK, Goeppert A (2011) J Am Chem Soc 133:12881-12898

4. Everest DA (1997) Energy \& Environment, vol. 4. pp. 328-329.

5. Deffeyes KS (2006) Eco Econ 59:394-394

6. Habisreutinger SN, Schmidt-Mende L, Stolarczyk JK (2013) Angew Chem Int Ed 52:7372-7408

7. Neațu S, Agulló M et al. (2014) Int J Mol Sci 15:5246-5262

8. Halmann M (1978) Nature 275:115-116

9. Inoue T, Fujishima A, Konishi S et al. (1979) Nature 277:637-638

10. Hashemizadeh I, Golovko VB, Choi J et al. (2018) Chem Eng J 347:64-73

11. Camarillo R, Tostón S, Martínez F et al. (2017) J Supercrit Fluid 123:18-27

12. Zhao H, Chen J, Rao G et al. (2017) Appl Surf Sci 404:49-56

13. Sun Z, Wang H, Wu Z et al. (2018) Catal Today 300:160-172

14. Xiao L, Lin R, Wang $\mathrm{J}$ et al. (2018) J Colloid Interface Sci 523:151-158

15. Zhu S, Liang S, Bi J et al. (2016) Green Chem 18:1355-1363

16. Ha MN, Lu G, Liu Z et al. (2016) J Mater Chem A 4:1315513165

17. Guo Q, Zhang Q, Wang H et al. (2016) Catal Commun 77:118122

18. Tamaura T (1990) Nature 346:255-256

19. Chen H, Yang M, Tao S et al. (2017) Appl Catal B 209:648-656

20. Meng X, Wang T, Liu L et al. (2015) Angew Chem Int Ed $53: 11478-11482$ 
21. Li D, Haneda H, Labhsetwar NK et al. (2005) Chem Phys Lett 40:579-584

22. Pan X, Yang MQ, Fu X et al. (2013) Nanoscale 5:3601-3614

23. Shin HC, Oh JH, Choi BC et al. (2004) Phys Status Solidi $1: 3748-3753$

24. Liu L, Cheng Y, Liu Z et al. (2016) RSC Adv 6:83814-83819

25. Imhof A, Pine DJ (2015) Nature 389:948-951

26. Holland BT, Blanford CF, Stein A (1998) Science 281:538-540

27. Wang T, Meng X, Liu G et al. (2015) J Mater Chem A 3:94919501

28. Sang ES, Kim K, Oh S et al. (2004) Macromol Res 12:240-245

29. Li X, Zhen X, Meng S et al. (2013) Environ Sci Technol 47:99119917
30. Zheng Y, Zheng L, Zhan Y et al. (2007) Inorg Chem 46:6980-6986

31. Naeem M, Hasanain SK, Kobayashi M et al. (2006) Nanotechnology 17:2675-2680

32. Puleo F, Liotta LF, La PV et al. (2014) Phys Chem Chem Phys 16:22677-22686

33. Yang Y, Tao Q, Srinivasan G et al. (2014) ECS J Solid State SC 3:P345-P352

34. Kim W, Choi M, Yong K (2015) Sens Actuators B Chem 209:989-996

35. Xu L, Ha MN, Guo Q et al. (2017) RSC Adv 7:45949-45959

36. Tamaura Y, Tahata M (1990) Nature 346:255-256

37. Tabata M, Nishida Y, Kodama T et al. (1993) J Mater Sci 28:971974 